\title{
Autoimmune enteropathy and endocrinopathy-susceptibility to chronic infections syndrome
}

INSERM

\section{Source}

INSERM. (1999). Orphanet: an online rare disease and orphan drug data base. Autoimmune enteropathy and endocrinopathy-susceptibility to chronic infections syndrome. ORPHA:391487

Autoimmune enteropathy and endocrinopathy-susceptibility to chronic infections syndrome is an extremely rare, autosomal dominant immunological disorder characterized by variable enteropathy, endocrine disorders (e.g. type 1 diabetes mellitus, hypothyroidism), immune dysregulation with pulmonary and blood-borne bacterial infections, and fungal infections (chronic mucocutaneous candidiasis) developing in infancy. Other manifestations include short stature, eczema, hepatosplenomegaly, delayed puberty, and osteoporosis/osteopenia. 